\title{
The effect of the ISO 9002 system standard on South African food manufacturing
}

\author{
Rigard Steenkamp \\ Department of Business Management, University of South Africa, P.O. Box 392, Pretoria, 0003 South Africa
}

Received July 1999

\begin{abstract}
The objective of this investigation was to establish the effect of the International Organisation for Standarization (ISO) on food manufacturing. The in-depth investigation took the form of an exploratory and a descriptive study of SABS certification (with the focus on SABS ISO 9002) in the food manufacturing industry. A qualitative and quantitative approach was followed. The research strategy necessitated a personal survey in which all SABS certified food manufacturers were visited. The in-depth study required three measuring instruments to increase internal validity. The empirical study showed that, regardless of hard work, much documentation, fear of change, cost implications and culture problems, food manufacturers are very positive, loyal and committed to the system according to SABS ISO 9002. By integrating the results of the exploratory and descriptive studies, the primary positive outcomes were that culture in terms of participation, discipline and uniformity is a dimension that benefited very much; conformance to specifications showed an average improvement of up to $77 \%$; customer complaints decreased by $57 \%$, customer satisfaction improved and process efficiency improved by $10.4 \%$.
\end{abstract}

\section{Thtroduction}

The debate between 'believers' and 'non-believers' on the values of the International Organisation for Standardisation (ISO 9000) continues. This is regardless of the \pm 300000 organisations in 204 countries applying ISO 9000. This article uncovers some myths and ideologies masking possible misunderstandings of the standard and its effects/values.

Several research reports suggest that compliance with the standard has wide-ranging effects and is much more than a 'house cleaning tool'. The objective of this investigation was therefore to test the overall effect of ISO on food manufacturing. 'Real-life' values were established and measured against the theoretical values of the ISO 9000 model.

The in-depth investigation took the form of a qualitative and a descriptive study of the South African Bureau of Standards (SABS) certification (with the focus on SABS ISO 9002) in the food manufacturing industry. The research strategy necessitated a personal survey in which all SABS certified food manufacturers were visited and three measuring instruments were applied in order to increase validity. By consolidating the results of the qualitative and descriptive studies, the primary positive outcomes established values beyond suggested model values.

\section{Background to the food industry}

The agro-food-nutrition chain came about because it is not viable for most consumers to produce their own grain, vegetables, milk and other food. Consequently, the chain consists of the farmer/fisherman, the food manufacturer and the consumer, each of whom fulfils an important role in establishing different food quality dimensions through one or other quality management system. The focus of the study was on the second link in the chain, consisting of the food manufacturer (food processing and food preserving segments to whom ISO 9002 applies), which provides the chain stores. The third link in the chain consists of food science, dietetics, home industries, catering, cookery and the preparation of food for domestic, commercial and institutional consumption.
The need for quality in the food industry lies in the urgency for nutrition, hygiene, market/export standards and the elimination of food wastage. The study also arose from an empirical study done by the quality manager of Woolworths (Pty) Ltd into the strategic necessity for quality control by South African food manufacturers (Ervine, 1991).

Possible cases (or incidences) of food poisoning necessitate the application of professional quality management in South Africa (as a Third World country with First World elements). First World standards are increasingly threatened. Foods like eggs, chicken, turkey and mixed meats in pies (pastries) and sausage are fertile breeding grounds for the harmful bacteria Salmonella sp. The same foods (except eggs) are also chiefly responsible for the propagation of the bacteria Clostridium perfringens. Another common problem in developing communities is that in most cases the nutritional content (a food quality dimension) of the traditional diet does not meet minimum standards. Poor quality food leads to high mortality and disease rates. In addition, the population growth in these countries is very high, with the result that per capita food production drops continually.

The food manufacturer African Products found that it spent too much time and money on reprocessing and came to the realisation that strict quality management had to be replaced by a quality assurance management system. All three mills concerned were successfully certified to SABS ISO 9002 in October 1991 . Although $8 \%$ of the products still barely scraped by on meeting the required specifications, African Products showed a 66\% improvement in this regard (Walbrugh. 1992). This led to further investigation of this case study and the effects of ISO 9002 on the other certified food manufacturers.

\section{ISO 9000 model}

The next section summarises the theoretical values (the effects it should have) of the ISO 9000 standard in general. The standard is described by values A, B and C, and will be used as the core benchmark for the empirical effects of the SABS ISO 9002 standard on the food manufacturer (see the 
fifth section of this report). Reference is made to ISO 9002 (1994) which is the quality system standard and model for quality assurance in production and installation.

\section{A. Objectives of the SABS ISO 9002 system standard (see value $A$, Table 9)}

The purpose of ISO 9002 (or SABS ISO 9002 in South Africa) is to provide manufacturers with a standard that will enable them to implement or measure their quality management system (QMS) against an international standard and to give internal and external clients/purchasers in the global industry the peace of mind of a professional quality assurance (QA) system. The purpose of the standard lies in internal and external QA (in the case of external audits done on the QMS) and in serving as a common denominator of business quality that is accepted internationally. Assured quality implies customer satisfaction and no product returns.

Specifically, the objectives of SABS ISO 9002 refer to four aspects: knowledge of and focus on non-conformities; prevention of any non-conformity during production; traceabilty of any non-conformity; and application of methods to prevent recurrence of any non-conformity.

\section{B. Values of the integrated overall system (see value B, Table 9)}

The challenge for a food manufacturer (and any ISO business organisation) is to reap the benefits of a well-designed QMS with all elements (sub-systems) working together. The ingredients (documented ISO 9000 system elements e.g. 4.1, 4.2 and 4.3) were carefully selected and internationally standardised, but there are uncertainties about customising these for individual users. The intention of ISO 9000 is to be an organised whole, an assemblage of system elements interacting in a co-ordinated way, so that the whole is more than the sum of the individual elements.

The operations management discipline focuses on adding value through transformation processes (whether human or complicated production line processes). This emphasises that all work or all valuable output is created by a process, puts the focus of ISO 9000 on process control (element 4.8). One approach to QA is coldly systematic and rigid, but it is now being replaced by a system in which processes have owners (internal customers) and should have responsible parties. This puts the focus on the human element (and work culture) and should have a stronger people focus where methods and procedures are coupled directly to the internal customer. Nicholas (1990: 56) refers to system principles or concepts and provide an understanding of system values and why systems (e.g. ISO 9000) perform well or not. These system concepts places systems in perspective and are: system elements (e.g., $4.1,4.2$ and 4.3 of ISO 9000), system attributes, system environment, system objectives (e.g., ISO is a foundation and not a model for TQM), system constraints, open and closed systems and man-made systems.

\section{Values of ISO 9000 sub-system elements (see value C. Table 9)}

The comprehensive quality management system standard has several (18) ISO 9002 elements (e.g., 4.1 management responsibility, 4.2 quality system, 4.3 contract review, 4.4 document control, 4.5 purchasing, 4.15 quality records, 4.8 process control, 4.18 statistical techniques) and is documented in the SABS ISO 9000 series of standard documents. The purpose of each element (or sub-system) mentioned above is self explanatory and the focus should be on overall system objectives, since each unique system standard element may have little value in itself.

Table 9 consolidates the empirical research results to identify ISO 9002 values (A, B and C).

\section{Research statement and research methods} Introduction to the problem

The second section provides some background to the need for improving and maintaining food quality through acknowledged QMS's. But increasing emphasis on standards, such as ISO 9000 , elicits the most controversial comments. It is generally agreed that it (or any other QMS) forms a good foundation for total quality management (TQM) and 'systems' is identified as one of three 'hard components' for TQM (Oakland, 1993). Critics say an ISO QMS should add more value and have more visible bottom-line benefits. The plague of multiple assessments, which has burdened companies, also causes some negativity. Some see ISO 9000 cost to doing business and not a sign of quality (a simplistic approach to an important and complex need). Others even regard ISO 9000 as a needless bureaucracy that has no positive impact on performance and see it as a whole new no valueadded industry of auditors and consultants.

\section{Research problem and objective}

The perception that ISO 9000 is only a marketing tool and that several more sophisticated quality management systems may exist can be added to the list of criticisms in the previous section. These concerns and the problem of very few SABS ISO certified food manufacturers in South Africa led to the 'Managing food quality assurance' symposium held by the SABS (Du Plessis, 1992). The SABS and the Department of Food Science of the University of Stellenbosch staged this event because of the uncertainty about the value that SABS ISO QMS's have for food manufacturers and led to the initiation of this investigation.

Consequently, the primary aim of this study was to determine the overall effects/values of the international QMS standard at all SABS-certified South A frican food manufacturers empirically. Non-certified or non-TQM food manufacturers' performance was excluded.

\section{Research strategy}

A qualitative and quantitative approach was followed and the strategy therefore entailed a personal survey in which every SABS-certified food manufacturer was visited. Coertze (1994: 162) refers to the phenomenological approach, which explains qualitative data collection techniques and the researcher as the principal instrument. A personal survey consequently presents the opportunity to use visual material, to explain (clarify) for effective control and the benefits of physical presence and appearance. Mouton \& Marais (1989: 43) state that an open and flexible research strategy should be followed if a study is aimed at gaining additional insight and understanding. Top-level informants and elite figures (role 
players or management of SABS-certified food manufacturers with practical experience) of the analysis unit were visited personally. Qualitative data not suitable for statistical analysis were processed qualitatively. In this way quantitative values were awarded to non-numerical features of human behaviour.

\section{Research methods and statistical analysis applied}

Three measuring instruments, namely observation, interviews and comprehensive questionnaires, were used to obviate possible shortcomings of one measuring instrument. Intermethodical cross-validation, by the inclusion of three datagathering methods (measuring instruments) for different types of information (e.g., incidence and frequency distributions), overcame the restrictions of a single method. The scope of the study entailed research of contextual concern for internal validity.

The SAS (Statistical Analysis System) PROC CORR program was used to test data and do a statistical analysis of the data gathered from the structured questionnaire. The questionnaire was comprehensive with 20 main questions of which six were qualitative questions. The questions were designed and tested by role players of Unisa (Coetzee, 1994) and the SABS to determine the reliability of the intrument. Each question had sub-questions (referred to as variables) totalling 169. A five-point scale applied as indicated in Table 1.

T-tests were done to establish whether there was a significant difference between two groups of role players (top and middle management). Then the $r$, Pearson Correlation Coefficient (the Pearson product moment-correlation coefficient index) was calculated between pairs of variables (e.g. ISO 9002 system elements). According to Hays (1963: 499), this is one of the better-known indexes of the correlative connection/relationship/link between two variables. A positive correlative connection provides an indication of system integration as opposed to isolated system elements. A correlational analysis (of questionnaire data) between system elements served as indicators (positive or negative) of relationships between elements and were presented as indicated in Table 2.
Another objective was to identify other important insights such as the important individual sub-system elements identified through a factor analysis and qualitative questions. A main component analysis (similar to a factor analysis) based on correlations was carried out to reduce the data to a more manageable form and determine significant cohesion between variables (Mulaik, 1972). The 'Rotation method: Varimax' is used to reduce data to a 'Rotated Factor Pattern'.

\section{Survey data of the analysis unit}

The detail of the analysis unit is provided in Table 3.

\section{Consolidated results}

The results have been consolidated according to (1) the qualitative aspects from observation, qualitative questionnaire data and interviews and (2) the descriptive study (only questionnaire data)

\section{Summarised results of the qualitative survey}

Several significant positive personal observations were made about the value of SABS ISO 9002 from the overall number of 51 observations ( 17 factories $\times 3$ observation categories). Some of these observations are that new equipment (laboratories and production lines) were commissioned as a result of the ISO system; improved calibration of equipment; evidence of the application of SPC (statistical process control); experiential knowledge of highly positive attitudes (e.g., through testimonies shared); the value of the QMS regarded as a general management system; QWL (quality of work life) advantages (e.g., good work environment; cleanliness/hygiene) and several other indications that a positive work culture exists. Other significant positive indicators from observation and the factory visits as a whole are:

- There is a possessiveness about the QMS and perceptions that the system offers job security and increases QWL.

- Various food manufacturers assist certification by other manufacturers.

- There is a healthy work culture of participation, unanimity and spontaneous problem solving. Eight of the 17 factories significantly confirmed work culture.

Table 1 A five-point scale applied as indicated

\begin{tabular}{|c|c|c|c|c|}
\hline 0 & 1 & 2 & 3 & 4 \\
\hline No value & $\rightarrow \rightarrow \rightarrow$ & $\rightarrow \rightarrow \rightarrow$ & $\rightarrow \rightarrow \rightarrow$ & high value \\
\hline No advantage & $\rightarrow \rightarrow \rightarrow$ & $\rightarrow \rightarrow \rightarrow$ & $\rightarrow \rightarrow \rightarrow$ & multiple advantages \\
\hline No improvement & $\rightarrow \rightarrow \rightarrow$ & $\rightarrow \rightarrow \rightarrow$ & $\rightarrow \rightarrow \rightarrow$ & highly significant improvement \\
\hline No effect & $\rightarrow \rightarrow \rightarrow$ & $\rightarrow \rightarrow \rightarrow$ & $\rightarrow \rightarrow \rightarrow$ & highly positive effiect \\
\hline-- & - & 0 & + & ++ \\
\hline Very negative effect & negative & neutral & positive & very positive effect \\
\hline
\end{tabular}

Table 2 Correlations between Q3 (question 3) for example, and the other variables

\begin{tabular}{lccccc}
\hline Two sub-questions & $\mathrm{r}$ & $\mathrm{p}$-value & Two sub-questions & $\mathrm{r}$ & p-value \\
\hline Q3D + Q5D & 0.8126 & 0.0001 & $\mathrm{Q} 3 \mathrm{D}+\mathrm{Q9F}$ & 0.8126 & 0.0018 \\
Q9L + Q3D & 0.7033 & 0.0016 & $\mathrm{Q} 31+\mathrm{Q} 11 \mathrm{C}$ & 0.7033 & 0.0002 \\
Q11J + Q3F & 0.6801 & 0.0027 & $\mathrm{Q} 3 \mathrm{G}+\mathrm{Q14C}$ & 0.6801 & 0.0023 \\
\hline
\end{tabular}


Table 3 Survey data of the analysis unit

$\begin{aligned} & \text { The percentage of SABS-certified food manufacturers who } \\ & \text { participated in the survey: }\end{aligned}$
$\begin{aligned} & 100 \% \text { (total } \\ & \text { population }=17)\end{aligned}$
manber of role players (elite figures) identified per food
$\begin{aligned} & \text { Maximum number of role players who could participate in the } \\ & \text { survey }\end{aligned}$
$\begin{aligned} & \text { Percentage of role players who participated in the } \\ & \text { questionnaire survey: } \\ & \text { Percentage of role players who participated in the interviews: }\end{aligned}$

Table 4 Basic statistics of the non-qualitative questions

\begin{tabular}{|c|c|c|c|c|c|}
\hline Variable & Average & $\begin{array}{l}\text { Standard } \\
\text { deviation }\end{array}$ & Variable & Average & $\begin{array}{l}\text { Standard } \\
\text { deviation }\end{array}$ \\
\hline Q2A & 2.3872 & 0.8431 & QIIA & 3.1225 & 0.7672 \\
\hline Q2B & 2.0441 & 0.7615 & QIIB & 3.6323 & 0.3964 \\
\hline $\mathrm{Q} 2 \mathrm{C}$ & 2.6568 & 0.6051 & QIIC & 3.5343 & 0.4886 \\
\hline Q2D & 2.7352 & 1.0018 & QIID & 4.0980 & 0.4697 \\
\hline Q2E & 1.3823 & 0.9138 & QIIE & 2.6323 & 0.6257 \\
\hline Q2F & 2.2156 & 0.9376 & $Q 11 F$ & 2.8578 & 0.5839 \\
\hline Q2G & 2.5098 & 0.8067 & Q11G & 2.7647 & 0.4798 \\
\hline $\mathrm{Q} 2 \mathrm{H}$ & 1.7254 & 0.9501 & QIIH & 2.7401 & 0.6008 \\
\hline Q2I & 1.7990 & 0.4123 & Q111 & 2.6666 & 0.6319 \\
\hline - & - & - & Q11J & 2.6372 & 0.6653 \\
\hline - & - & - & QIIK & 2.8382 & 0.6370 \\
\hline- & - & - & Q11L & 3.7058 & 0.5944 \\
\hline- & - & - & Q1IM & 3.3431 & 0.6665 \\
\hline - & - & - & QIIN & 3.1421 & 0.6671 \\
\hline- & - & - & Q110 & 2.8431 & 0.6406 \\
\hline Q3A & 3.6764 & 0.4123 & Q12A & 2.7352 & 0.6341 \\
\hline Q3B & 1.8382 & 1.0114 & Q12B & 1.9852 & 0.9077 \\
\hline Q3C & 3.0147 & 0.6341 & $\mathrm{~A} 12 \mathrm{C}$ & 2.8333 & 0.7660 \\
\hline Q3D & 3.4019 & 0.5584 & Q12D & 2.8578 & 0.7051 \\
\hline Q3E & 2.5147 & 0.6402 & $\mathrm{Q} 12 \mathrm{E}$ & 2.2401 & 0.8159 \\
\hline Q3F & 2.7941 & 0.7512 & $\mathrm{Q} 12 \mathrm{~F}$ & 2.4362 & 0.8012 \\
\hline Q3G & 2.6568 & 0.8394 & Q12G & 2.2303 & 1.0006 \\
\hline Q3H & 3.2696 & 0.6760 & $\mathrm{Q} 12 \mathrm{H}$ & 2.2892 & 0.8323 \\
\hline Q31 & 3.2647 & 0.6025 & Q12I & 1.6911 & 0.9417 \\
\hline Q3J & 3.5147 & 0.5189 & Q12J & 1.8235 & 1.1276 \\
\hline- & - & - & Q12K & 2.2549 & 0.9818 \\
\hline Q5A & 4.0294 & 0.4667 & Q14A & 3.3039 & 0.3952 \\
\hline Q5B & 3.8872 & 0.6996 & Q14B & 1.4166 & 1.2383 \\
\hline Q5C & 3.7990 & 0.5393 & Q14C & 2.3137 & 0.9675 \\
\hline QSD & 4.2058 & 0.5465 & Q14D & 2.8872 & 0.9353 \\
\hline QSE & 3.9411 & 0.4721 & Q14E & 3.4558 & 0.5811 \\
\hline QSF & 4.4509 & 0.5512 & Q14F & 2.8774 & 0.8999 \\
\hline Q5G & 3.6666 & 0.4956 & Q14G & 2.1421 & 1.2457 \\
\hline QSH & 3.0147 & 0.5036 & Q14H & 3.3627 & 0.8052 \\
\hline QSI & 3.9607 & 0.6017 & Q14I & 2.5196 & 0.9263 \\
\hline QSJ & 3.7990 & 0.4939 & - & - & - \\
\hline Q5K & 4.1176 & 0.5009 & - & - & - \\
\hline Q5L & 3.8235 & 0.5503 & - & - & - \\
\hline Q6A & 3.6568 & 0.4884 & QISA & 3.0735 & 0.6044 \\
\hline Q6B & 3.4460 & 0.7162 & Q15B & 3.0245 & 0.5971 \\
\hline Q6C & 3.8774 & 0.4019 & Q15C & 3.2745 & 0.5202 \\
\hline Q6D & 3.0735 & 0.5780 & Q15D & 2.9509 & 0.7424 \\
\hline Q6E & 4.4068 & 0.6877 & QI5E & 2.6715 & 0.6478 \\
\hline
\end{tabular}

Frequencies of positive main components from the interviews were determined after related variables were grouped and reduced to single components. They are work culture (focus on non-conformities and prevention) and process control (of any non-conformity during production and traceabilty of any non-conformity). These components achieved the highest frequencies as main components in the interviews and discipline (records and the application of methods to prevent recurrance of any non-conformity), uniformity and 'foundation for stability' are the second group with high frequencies. The

Table 4 Basic statistics of the non-qualitative questions

\begin{tabular}{|c|c|c|c|c|c|}
\hline Variable & Average & $\begin{array}{l}\text { Standard } \\
\text { deviation }\end{array}$ & Variable & Average & $\begin{array}{l}\text { Standard } \\
\text { deviation }\end{array}$ \\
\hline Q6F & 4.1519 & 0.6668 & $Q / 5 F$ & 3.4215 & 0.6437 \\
\hline Q6G & 3.6176 & 0.6194 & Q15G & 3.1862 & 0.5578 \\
\hline Q6H & 4.0147 & 0.4095 & - & - & - \\
\hline Q61 & 4.2647 & 0.4798 & - & - & - \\
\hline Q6J & 3.9019 & 0.5096 & - & - & - \\
\hline Q6K & 2.5833 & 0.8799 & - & - & - \\
\hline Q6L & 3.9460 & 0.6653 & - & - & - \\
\hline Q6M & 2.7009 & 0.8159 & - & - & - \\
\hline Q8A & 1.0294 & 0.1212 & Q16A & 3.5539 & 1.3277 \\
\hline Q8B & 1.0882 & 0.2154 & Q16B & 5.0294 & 0.5367 \\
\hline Q8C & 1.0931 & 0.2202 & Q16C & 4.5686 & 0.8160 \\
\hline Q8D & 1.8382 & 0.2490 & Q16D & 4.5490 & 0.9943 \\
\hline Q8E & 1.1274 & 0.1979 & QIGE & 3.7647 & 1.2102 \\
\hline Q8F & 1.0686 & 0.1420 & $Q \mid 6 F$ & 4.3137 & 1.1631 \\
\hline- & - & - & Q16G & 3.9901 & 1.0466 \\
\hline- & - & - & Q16H & 3.5833 & 1.2335 \\
\hline Q9A & 0.8088 & 0.6029 & $Q 18 A$ & 3.5196 & 0.4315 \\
\hline Q9B & 2.7598 & 0.8222 & Q18B & 3.0098 & 0.4408 \\
\hline Q9C & 2.7107 & 0.7604 & $Q \mid 8 C$ & 3.0686 & 0.7176 \\
\hline Q9D & 2.9509 & 0.8333 & Q18D & 3.5245 & 0.4812 \\
\hline Q9E & 3.2549 & 0.8387 & QI8E & 3.3480 & 0.4780 \\
\hline$Q 9 F$ & 3.1911 & 0.9500 & Q18F & $3 / 2843$ & 0.5559 \\
\hline$Q 9 G$ & 2.2352 & 0.7978 & Q18F & 3.3823 & 0.5086 \\
\hline Q9H & 1.9607 & 0.9789 & $\mathrm{Q} 18 \mathrm{H}$ & 3.3039 & 0.3460 \\
\hline Q9I & 1.8480 & 0.8966 & - & - & - \\
\hline Q9J & 2.5882 & 0.88 .36 & - & - & - \\
\hline Q9K & 2.9901 & 0.8046 & - & - & - \\
\hline Q9L & 3.1911 & 0.8728 & - & - & - \\
\hline Q9M & 3.1274 & 0.6673 & - & - & - \\
\hline Q9N & 3.1666 & 0.7761 & - & - & - \\
\hline Q9O & 2.4117 & 0.7952 & - & - & - \\
\hline Q9P & 2.8725 & 0.8037 & - & - & - \\
\hline Q10-1 & 4.5994 & 2.0047 & $\mathrm{Q} 20 \mathrm{~A}$ & 2.0885 & 1.1169 \\
\hline${ }^{*} \mathrm{Q} 10-2$ & 4.3491 & 1.9717 & Q20B & 1.0000 & 0.8660 \\
\hline${ }^{*} \mathrm{Q} 10-3$ & 3.5918 & 1.5924 & $Q 20 C$ & 2.0973 & 1.3002 \\
\hline${ }^{\circ} \mathrm{Q} 10-4$ & 4.0042 & 1.5696 & Q20D & 1.2916 & 0.8612 \\
\hline Q10-5 & 7.2641 & 1.2934 & Q20E & 2.1197 & 1.0911 \\
\hline Q10-6 & 5.0614 & 1.8188 & - & - & - \\
\hline Q10-7 & 4.6709 & 1.5109 & - & - & - \\
\hline Q10-8 & 5.5815 & 1.7878 & - & - & - \\
\hline Q10-9 & 6.6136 & 2.7488 & - & - & - \\
\hline Q10-10 & 9.26 .36 & 0.7855 & . & - & - \\
\hline
\end{tabular}


positive-related five main components identified from the data of the interviews, display a strong connection with the aspects of the four shared areas (discussed in third section) of the objectives of the quality management system, which is a corroborative indication that the system, according to SABS ISO 9002 , achieves its goal.

The negative main components from the interviews and qualitative questionnaire data are hard work, administration, a lot of documentation, high costs and the difficulty of implementation/maintenance of the system frustrate the certified food manufacturers. The reasons given for delaying certification are lack of information, fear of change, incapacity, hard work, inadequate standards, high costs, unsuitable internal culture and complacency resulting in present (own) existing standards being considered adequate.

The qualitative questionnaire data provided evidence of before-after improvements (e.g., percentages on conformity to specifications, client satisfaction trends and others), and will be discussed/added in the sixth section (discussion of results).

\section{Summarised results of the descriptive study}

The t-test showed that there is no significant difference between top management and the rest (mainly middle management). The data set could thus be used as a unit. From the basic scale statistics of each structured question (Table 4) and significant positive correlations ( $r$ ) of each sub-question measurements with other sub-questions, several deductions could be made. The significant measurements based on scale statistics and high positive correlations are selectively included. A summary of the basic statistics of the questionnaire data ( 14 non-qualitative questions) is given in Table 4.

The priority analysis (see* Q10 of Table 4 ) indicated variables Q10-3, Q10-4 and Q10-2 (in priority sequence). This indicates preventive actions, work culture and process efficiency would be used to 'convince non-listed food manufacturers of ISO 9002' (question 10). The primary focus of the implementation process, though, were on three main aspects, namely: certification (Q14A); customer satisfaction (Q14E) and product quality $(\mathrm{Q} 14 \mathrm{H})$ and it could be deduced that their expectations were exceeded if all the values of the system is considered.

The main component analysis revealed two main components, namely corrective actions and control through effective documentation (see factor $\mathrm{E}$, Table 6) as well as post- production functions (handling, packaging and delivery). The questions (and variables included in factor E) of Q9 measured the degree ISO 9002 changed the elements indicated in Table 5.

Table 5 Elements of question 9 included in factor $E$

\begin{tabular}{|c|c|c|c|c|c|}
\hline & \multirow{2}{*}{$\frac{\text { No }}{0}$} & \multicolumn{2}{|c|}{ Change } & \multicolumn{2}{|c|}{ Positive } \\
\hline & & 1 & 2 & 3 & 4 \\
\hline E. Improved procedures & & & & * & \\
\hline F. Quality records & & & & * & \\
\hline K. Incoming material control & & & * & & \\
\hline L. Corrective action & & & & * & \\
\hline M. Effective documentation & & & & * & \\
\hline N. Handling of non-conformity & & & & $*$ & \\
\hline
\end{tabular}

Table 6 indicates the high cohesion between variables for factor $E$.

Table 6 High cohesion between variables for factor $\mathrm{E}$

\begin{tabular}{lll}
\hline Q9N & with & 0.94 \\
Q9M & with & 0.88 \\
Q9F & with & 0.85 \\
Q9L & with & 0.82 \\
Q9E & with & 0.74 \\
Q3D & with & 0.66 \\
Q9K & with & 0.63 \\
\hline
\end{tabular}

By looking concretely and comprehensively at the results of the other questions in the questionnaire, the value of the QMS for the food manufacturers in terms of customer satisfaction (e.g., Q14E rated 3.4558) and work culture. became clear. Table 7 indicates how the enterprise gained by the implementation of a quality management system based on SABS ISO 9002.

Table 7 Value of the QMS in terms of working culture, enterprise image and customer satisfaction

\begin{tabular}{|c|c|c|c|c|c|}
\hline & \multicolumn{2}{|l|}{ No } & \multicolumn{2}{|c|}{ Improvement } & \multirow{2}{*}{ Major } \\
\hline & 0 & 1 & 2 & 3 & \\
\hline Q2C. Working culture & & & & $*$ & \\
\hline Q2D. Enterprise image & & & & * & \\
\hline Q2G. Customer satisfaction & & & & $*$ & \\
\hline
\end{tabular}

The value of the quality management system (measured by Q5) is also high with respect to continuous improvement (Q5D), which is linked ( $r=0.8126)$ to quality documentation and records (Q3D). Q5F also indicates records (with a value of 4.4509) and hygiene (with a value of 4.1176). A summary of significant Q5 variables is given in Table 8 .

Table 8 Value of the QMS in terms of continuous improvement, documentation and hygiene

\begin{tabular}{|c|c|c|c|c|c|}
\hline & \multirow{2}{*}{ No } & \multicolumn{2}{|c|}{ Value } & \multicolumn{2}{|c|}{ High } \\
\hline & & - & 0 & + & ++ \\
\hline D. C ontinual improvement (Kaizen) & & & & & * \\
\hline E. Public relations & & & & * & \\
\hline F. Quality data (records) & & & & & * \\
\hline I. Reduction of rework & & & & * & \\
\hline K. Hygiene & & & & & * \\
\hline
\end{tabular}

Questions 7 and 17 (qualitative question) measured the important (outstanding) quality management sub-systems. Both questions provided the same elements. Question 7 also asked for a link to a certain value (e.g. responsibility of management was linked to promoting internal relations). Four of the 
18 SABS ISO 9002 elements were identified. They were identified as element 4.1 , which is responsibility of management (which promotes internal relations), element 4.8 which is process control (which was linked to a decrease of wastage and a reduction of cost), element 4.9 which is inspection and tests (which promotes customer satisfaction and compliance with specifications) and element 4.13 which is corrective action (which promotes prevention of defects).

Other variables worth mentioning are the importance of training $(\mathrm{Q} 3 \mathrm{~A}$ and $\mathrm{Q} 11 \mathrm{~L})$ and that continuous improvement (Q5D) also applies to the learning curve of human resources. The human element (and variations thereof) is identified repeatedly, such as 'top management commitment precedes total quality' (Q15F rated 3.4215), 'get to know the internal customer' (Q11D rated 4.0980), 'immediate feedback of defects to the responsible person' (Q12D rated 2.8578) and respect for food (Q16C rated 4.5686).

Finally, Q6 measured ISO 9002 holistically (the degree to which the following statements are regarded as true with regard to a quality management system according to SABS ISO 9002, in general). The variables with high scores were: Q6E 'Applicable (valid) for the food industry'; Q6F 'Listed food manufacturers will increase in the food industry'; $\mathrm{Q} 6 \mathrm{H}$ 'Is an effective quality model in itself' and Q6I 'Has numerous qualitative advantages'.

With reference to the third section (theoretical values $\mathrm{A}, \mathrm{B}$ and $C$ of the model of the ISO 9000 system) the emperical results can be consolidated as indicated in Table 9.

\section{Discussion of results}

The entire empirical survey reveals that, despite the hard work, lots of documentation, fear of change and cost implications, the food manufacturers seem to be very positive and committed to the ISO 9002 QMS. Data from the total number of observations and the questionnaire (Q6) provided substantial confirmation (and surprising observations according to section 5.1) of its positive value to the food industry.

\section{Work culture}

To integrate the surveys, analysis of the results indicates a strong human dimension and a stronger connection between internal customers. If only a few values are to be identified, the first would thus be work culture. The interviews also indicated culture-related main components (participation, uniformity, control and discipline). Work culture (Q2C) (and see $\mathrm{MM}$ of Table 9) has a strong relationship $(r=0.9213)$ to

Table 9 Emperical results consolidated

\begin{tabular}{|c|c|c|c|c|c|}
\hline \multirow{2}{*}{$\begin{array}{l}\text { ISO } 9002 \text { MODEL VALUES } \\
\text { A. System objectives }\end{array}$} & \multicolumn{5}{|c|}{ MEASURING INSTRUMENTS } \\
\hline & $\overline{\mathrm{OB}}$ & QQ & 1 & QS & MM \\
\hline Focus on and prevention of any non-conformity during production & & + & + & + & + \\
\hline Traceabilty of any non-conformity & & & + & + & \\
\hline Application of methods/procedures & & & + & + & \\
\hline Prevent re-occurence of any non-conformity & & & + & + & \\
\hline \multicolumn{6}{|l|}{ B. Values of the integrated overall system } \\
\hline Work culture & + & & + & + & + \\
\hline Uniformity/consistency & & & + & + & \\
\hline Stability/foundation paves the way for continuous improvement & + & & + & + & + \\
\hline Participation/co-ordination & + & & + & + & + \\
\hline Integration and unity with business system & + & & + & + & + \\
\hline \multicolumn{6}{|l|}{ C. Values of sub-system elements } \\
\hline Responsibility of management (element 4.1) & & & + & + & \\
\hline Process control (element 4.8 ) & & + & + & + & + \\
\hline Inspection and tests (element 4.9) & & & & + & \\
\hline Corrective action (element 4.13) & & + & & + & \\
\hline Document control (element 4.4) & & & & + & \\
\hline Post production functions (handling, packaging and delivery) & & & & + & \\
\hline \multicolumn{6}{|l|}{ D. Other qualitative values } \\
\hline Improvements like new equipment, laboratories and production lines & + & & + & & \\
\hline QWL (quality of work life) advantages & + & + & + & + & + \\
\hline \multicolumn{6}{|l|}{ Significant positive before/after statistics on: } \\
\hline Conformance to specs & & + & & + & \\
\hline Customer complaints & & + & & + & \\
\hline Process efficiency (less wastage & & + & & + & \\
\hline Food quality dimensions improved & & + & & + & \\
\hline
\end{tabular}


participation (Q9C). Internal relations and internal customer satisfaction are also confirmed as interchangeable concepts. The quality of work life (QWL) advantages (see MM of Table 9) and healthy work culture, which results from the QMS as a whole, precedes spontaneous actions and the implementer should ideally tackle this dimension (culture) earlier in the certification process. 'Culture precedes quality output' (Q15A) has a strong correlation $(r=0.9579)$ with 'values precedes actions' (Q15B). This will facilitate the implementation process of the ISO 9002 quality management system. The 'work culture' variable also indicates the ideal relationship $(r=0.9213)$ with the quality management principle, 'prevention'. Training (continuous quality improvement of human resources) is also identified as a value.

\section{Quality economy and process efficiency through control}

Quality economy (the internal and external cost of quality) refers to doing things right initially (the first time). The priority analysis identified 'prevention' and 'process efficiency' as two of the three most important values and process efficiency improved by up to $10.4 \%$ (according to quantitative figures provided). This is due to process control (element 4.8) (see MM of Table 9), which is the essence of operations (valueadding transformation processes) and this element 'process control' is also identified as one of the most important system elements. Control over measuring and test equipment are also regarded as important elements of the system. Reduction of food wastage (Q2B) has a strong relationship $(r=0.8538)$ to prevention of defects (Q9B) and Q9B correlates highly $(r=$ 0.8819 ) with customer satisfaction. It can thus be said that the ISO 9002 model is not only a quality assurance (QA) model for the external customer, but also an internal QA model for the internal customer. The system offers a foundation (system platform) for further improvement and preventive actions. The qualitative data also indicated, among other things, that customer complaints drop by up to $57 \%$.

\section{Improved procedures and documentation}

Many business organisations resist ISO 9000 because of the system's documentation. Better procedures (as documented) have a positive relationship to the economy of quality because procędures consume resources, and must be effective. The important relationship between better procedures and documentation (records) $(r=0.8745)$ is the three positive aspects that are changed most by the implementation of the
QMS and which offer the basis for the system and the benefits of the system.

\section{Food quality}

There is a positive link between process quality and food quality. Various improvements made to production processes led to better food quality. 'Product quality' (Q14H) has a strong relationship $(r=0.8869)$ to 'process efficiency'. Conformity to specifications shows an average improvement of up to $77 \%$ and the specific improved food quality dimensions were appearance, taste and hygiene.

\section{Conclusion}

The study confirmed core values suggested by the model of the ISO 9000 system (see third section) and several additional values. It is also clear that a ISO 9002 QMS should form a primary base for stability on the way to TQM for the food manufacturer. The future and essence of ISO 9000 should not change much.

\section{References}

Coetzee, C.H. 1994. Researcher, Department of Psychology, University of South Africa, Pretoria. Personal interview, May.

Coertze, R.D. 1994. Deelnemende waarneming: deelname en/of ondervraging. Lesing gelewer tydens 'n kursus in Navorsingsmetodiek, aangebied deur die Universiteit van Pretoria by die Absa Bank Sentrum vir Bestuurderontwikkeling, 28-31 Maart.

Du Plessis, J.P. 1992. President, Suid-A frikaanse Buro vir Standaarde, Pretoria. Persoonlike mededeling. 28 April.

Ervine, K. 1991. Nothing but the best. Food Review, August/September: 51-53.

Hays, W.L. 1963. Statistics. New York: Holt, Rinehart \& Winston. ISO 9002, 1994. Quality system standard. Model for quality assurance in production, installation and servicing. Pretoria: SABS.

Mouton, J. \& Marais, H.C. 1989. Metodologie van die geesteswetenskappe: basiese begrippe. Pretoria: Insto-Print.

Mulaik, S.A. 1972. The foundations of factor analysis. New York: McGraw-Hill

Nichołas, J.M. 1990: Managing business and engineering projects: concepts and implementation. Englewood Cliffs. NJ: PrcnticeHall.

Oakland, J.S. 1993. Total quality management: the route to improving performance. London: Butterworth Heinemann.

Walbrugh, P.W. 1992. Right the second time. Paper delivered at the 6th Annual Symposium on Food Science held at the Lord Charles Hotel, Somerset West, 4 May. 